\title{
LAPAROSCOPY VERSUS LAPAROTOMY FOR THE MANAGEMENT OF EARLY STAGE CERVICAL CANCER. HOSPITAL DR SOTERO DEL RIO. CHILE
}

\author{
Drs Puga O, Perez MV, M, Saez N, Jensen R, M, Retamales J..
}

${ }^{1}$ Hospital Dr Sotero del Rio, Gynecology Oncology, Santiago, Chile. 2Pontificia Universidad Católica de Chile, Gynecology Oncology, Santiago, Chile

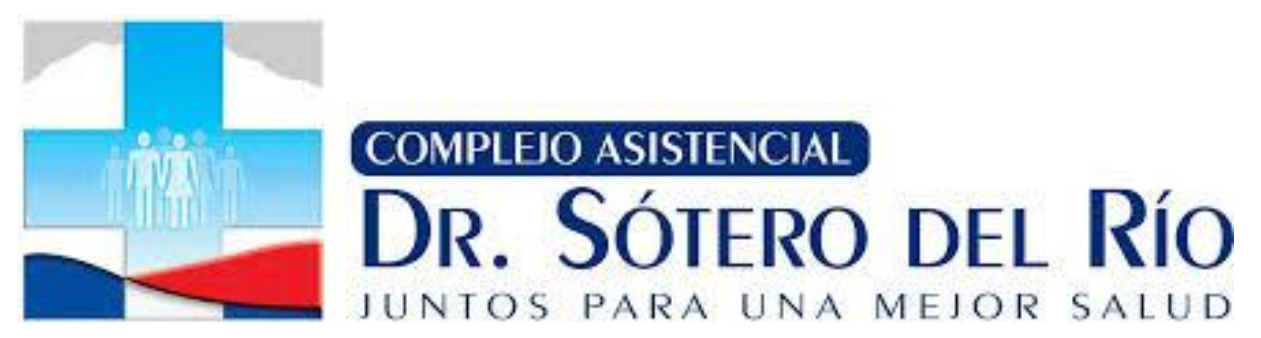

The treatment of early stage cervical cancer (IA2 to IIA) is surgical. Radical hysterectomy with bilateral pelvic lymphadenectomy is the standard recommendation. During the last 5 years we started a program to introduce the minimal invasive approach for these patients.

\section{Objetives}

To compare the feasibility, safety and surgical outcomes between laparoscopic surgery (LHR) and open laparotomy $(\mathrm{HR})$ in early stage cervical cancer

\section{Methods}

We performed a retrospective review of patients with early stage cervical cancer treated with radical hysterectomy and pelvic lymphadenctomy between 2013 and 2018 at the department of Obstetric and Gynecology of Hospital Dr Sótero del Rio, Santiago de Chile. We analyzed clinicals reports and statistical studies was performed

\section{Results}

We had 87 women with cervical cancer and surgical treatment. We performed 2 laparoscopic radical trachelectomies. Four patients were pregnant and had a $\mathrm{C}$-section prior to the $\mathrm{RH}$. Surgery was abandoned in 5 patients with positive pelvic lymph nodes, those patients had a para-aortic lymphadenectomy and four patients had no records.

We included 72 patients for analysis, 47 (65\%) had $\mathrm{LRH}$ and 25 (35\%) had $\mathrm{RH}$. FIGO stage included IA2 (4), IB1 (62), IB2 (3) and IIA1 (3).

Both groups were similar in age (mean 46, range 30 74), co-morbidities, histology (adenocarcinoma 29\%, squamous $70 \%$, adeno-squamous $1 \%$ ) and surgical stage. Two patients required conversion from $\mathrm{LRH}$ to $\mathrm{RH}$.

There were two ureteral injuries in both groups, 1 bowel injury in the LHR group, and 3 wounds infections and one obturator nerve sections in the $\mathrm{RH}$ group.

\begin{tabular}{|c|c|c|}
\hline Characteristic & Open surgery & $\begin{array}{l}\text { Laparoscopic } \\
\text { surgery }\end{array}$ \\
\hline Age & $49(30-74)$ & $45(31-67)$ \\
\hline Body mass index & $33(25-41)$ & $28(21-42)$ \\
\hline \multicolumn{3}{|l|}{ Histologic sub type } \\
\hline Squamus cell carcinoma & 15 & 36 \\
\hline Adenocarcinoma & 9 & 11 \\
\hline Adenosquamus carcinoma & 1 & \\
\hline \multicolumn{3}{|l|}{ Stage } \\
\hline IA2 & 1 & 3 \\
\hline IB1 & 20 & 42 \\
\hline IB2 & 2 & 1 \\
\hline IIA1 & 1 & 2 \\
\hline Hospital stay (hours) & 90 & $127(p=0.009)$ \\
\hline Estimated blood loss (ml) & 391 & $145(p=0.025)$ \\
\hline Operative time(min) & 231 & 223 \\
\hline Lymph nodes & 17 & 16 \\
\hline
\end{tabular}

There were no differences between BMI, lymph-nodes counts (17 vs 16) and operative time. No difference in adjuvant treatment (39\% in both arms). $\mathrm{LRH}$ requires less post-operative analgesia and the post-operative length of stay was shorter than $\mathrm{RH}(p=0,009)$. The mean estimated blood loss (EBL) was decreased in LRH (145 vs $391 \mathrm{~mL}, p=0.025$ ).

Conclusions:

Laparascopic radical hysterectomy has similar therapeutic efficacy compare to open radical hysterectomy, however it has more favorable surgical outcomes including less estimated blood loss, faster recovery and shorter hospital stay. Oncologic outcome requires longer follow up 